\title{
Anabases
}

ANABASES Traditions et réceptions de l'Antiquité

26 | 2017

Varia

\section{Pierre BRIANT, Alexandre. Exégèse des lieux communs}

Élodie Guillon

(2) OpenEdition

Journals

Édition électronique

URL : http://journals.openedition.org/anabases/6247

DOI : 10.4000/anabases.6247

ISSN : 2256-9421

Éditeur

E.R.A.S.M.E.

Édition imprimée

Date de publication : 1 novembre 2017

Pagination : 227-229

ISSN : 1774-4296

Référence électronique

Élodie Guillon, «Pierre BRIANt, Alexandre. Exégèse des lieux communs », Anabases [En ligne], 26 | 2017, mis en ligne le 01 novembre 2017, consulté le 20 janvier 2021. URL : http://journals.openedition.org/ anabases/6247 ; DOI : https://doi.org/10.4000/anabases.6247

Ce document a été généré automatiquement le 20 janvier 2021.

(c) Anabases 


\title{
Pierre BRIANT, Alexandre. Exégèse des lieux communs
}

\author{
Élodie Guillon
}

\section{RÉFÉRENCE}

Pierre BRIANT, Alexandre. Exégèse des lieux communs, Paris, Gallimard, Collection Folio histoire, 2016, 660 p. + 8 p. de pl., 11, 90 euros/ ISBN 978-2-07-079376-1.

1 Pierre Briant propose un ouvrage consacré à l'analyse des lieux communs sur Alexandre, dans la lignée de ses derniers travaux, en particulier Darius dans l'ombre d'Alexandre (2003) et Alexandre des Lumières. Fragments d'histoire européenne (2012). L'auteur évoque d'ailleurs la genèse de ce livre, plus ancienne encore - il la date des années 1990 -, et sa volonté de «faire sauter les verrous qui contraignent l'histoire d'Alexandre dans des bornes chronologiques et épistémologiques étroites et mutilantes». Pour cela il propose de revenir sur les lieux communs entourant Alexandre, dans un cadre spatio-temporel large, "l'Orient " et "l'Occident», de l'Antiquité à nos jours, en incluant des supports variés et originaux, écrits, iconographiques, cinématographiques... P. Briant rend compte ainsi d'une enquête foisonnante, à l'image du sujet, dont les développements, parfois denses, s'articulent en huit chapitres suivis d'une bibliographie conséquente et d'un index des noms.

2 Après une introduction utilement didactique, où l'auteur explicite son titre, ses objectifs et les fils conducteurs de l'ouvrage, un premier chapitre traite « les images du prince ». P. Briant revient aux artistes qu'Alexandre choisit pour le représenter, avant d'étudier les époques hellénistique et romaine, durant lesquelles Alexandre est imité, ou sert de figure d'émulation. P. Briant parcourt ensuite l'Europe, du Moyen Âge à l'époque moderne, où les images d'Alexandre se sont transmises, souvent utilisées comme exemple - ou contre-exemple - dans l'éducation morale et militaire des gouvernants. Au chapitre suivant, l'auteur sort de "l'étouffant entre-soi européen » pour étudier les images d'Alexandre devenu, par les multiples traductions et 
adaptations du Roman d'Alexandre, une référence culturelle et politique mondiale. Il aborde ainsi divers Iskender, Aliksandar ou Sikandar dans les versions persanes, ottomanes, byzantines, indiennes et malaises, avant de terminer sur une adaptation inédite du Romandécouverte au Mali.

Dans le troisième chapitre, l'auteur revient sur "le héros colonial », un sujet qu'il connaît bien. Il rompt la progression chronologique et géographique pour une analyse thématique de lieux communs, comme Alexandre le « civilisateur », le «libérateur des peuples» ou encore le «constructeur de routes». Le héros paraît finalement cristalliser les rêves et les peurs de l'Europe expansionniste, incarnant les rapports que celle-ci développe avec le reste du monde. Du côté européen, l'auteur montre bien la grande continuité des représentations gréco-romaines de l'opposition entre Europe et Asie, mais il ne néglige pas les oppositions et les contestations des peuples colonisés, ou dans l'historiographie des métropoles, impliquant également des images d'Alexandre.

Le chapitre "Médias et médiatisation » met en lumière l'actualité et l'actualisation de la figure d'Alexandre dans les sociétés contemporaines au travers de quatre médias : la musique heavy metal, les ouvrages de vulgarisation, et en particulier l'Alexandre de Benoist-Méchin, le cinéma, et enfin les musées et les grandes expositions consacrées au conquérant et à la Macédoine ces quarante dernières années. L'analyse de l'historien ici appliquée à des médias populaires permet de rendre compte de façon claire du décalage frappant entre le monde de la recherche et l'image véhiculée dans le grand public, nourrie des grands lieux communs explicités précédemment.

5 P. Briant présente ensuite sa "galerie d'experts ", que l'on a déjà rencontrés dans les chapitres précédents et qui ont marqué la perception historienne d'Alexandre, de Montesquieu jusqu'à Bosworth, en passant évidemment par Droysen. Pour chacun, le contexte et les filiations scientifiques sont retracées, tout comme les principaux apports dans l'étude d'Alexandre. Le chapitre suivant entre bien en résonnance, puisqu'il reprend les débats autour de la figure et de l'histoire du Macédonien, qui pourraient étonnamment se résumer dans la question de savoir si « Alexandre doit être admiré ou condamné ". La mise en perspective des débats dans la longue durée montre en effet une extrême continuité des jugements moraux suscités par le personnage. Puis le septième chapitre met en lumière le fait que l'instrumentalisation des images d'Alexandre à des fins politiques perdure jusque dans notre histoire immédiate. L'auteur présente, pour l'illustrer, deux exemples: l'intervention américaine en Afghanistan, rapprochée de la conquête de la Bactriane, et le conflit entre la Grèce et la République de Macédoine dans la revendication d'un héritage national d'Alexandre.

6 Le dernier chapitre, "Que faire?", vient conclure l'enquête. Les principaux lieux communs sur Alexandre y sont utilement résumés, avant que l'auteur ne propose de répondre à sa question. Ayant démontré l'impact de ces lieux communs sur notre perception du conquérant, et notre manière d'écrire son histoire, il recommande, pour dépasser à l'avenir la compilation de ces derniers, de revenir aux sources (historiques), tant gréco-macédoniennes qu'orientales. Ces dernières, si souvent oubliées ou méconnues, contribueraient pourtant à resituer le conquérant dans son histoire plus large, plus globale.

7 L'organisation générale de l'ouvrage, articulée en prologues et sous-parties thématiques, ainsi que les efforts continuels de l'auteur pour présenter systématiquement les contextes de création et de réception des images d'Alexandre facilitent la lecture de cette riche investigation, qui s'adresse aux spécialistes, mais qui 
est accessible aux néophytes. Un seul léger bémol, peut-être, serait l'organisation et la numérotation des illustrations, réparties au début du volume et au milieu, selon une logique peu perceptible. Au final, P. Briant réussit son pari, celui d'« ouvrir des fenêtres ", en livrant ici une enquête originale et efficace de réception de l'Antiquité, sur des horizons divers, complexes et parfois méconnus (le monde malais par exemple).

\section{AUTEURS}

\section{ÉLODIE GUILLON}

Université Toulouse - Jean Jaurès (UT2J)

eguillon31@gmail.com 